\title{
Highly Conductive Solvent-Free Polymer Electrolytes for Lithium Rechargeable Batteries
}

\author{
Phase-I Final Report
}

Grant No: DE-FG02-03ER83801

Work Period: July 21, 2003-April 20, 2004

Funding Agency:

Dr. Susan A. Rogers (EE-32)

U.S. Department of Energy

1000 Independence Ave., S.W.

Washington, DC 20585-0121

\section{Primary Contractor:}



TechDrive, Inc.

3255 South Dearborn Street

Suite 320

Chicago, IL 60616

Dr. Robert Filler, Principal Investigator

Senior Vice President

Ph: (312) 567-3910

Fax: (312) 567-7036

rfiller@techdrive.com 


\title{
Highly Conductive Solvent-Free Polymer Electrolytes for Lithium Rechargeable Batteries
}

\author{
Dr. Robert Filler \\ Principal Investigator \\ TechDrive, Inc.
}

\section{Identification and Significance of the Problem or Opportunity}

Requirements of SPE
The availability of lithium rechargeable batteries featuring solvent-free highly conductive solid polymer electrolytes (SPEs) will make a major impact on the electric and hybrid-electric vehicles (EV/HEV) industry, leading to a significant reduction in environmental pollution and improved performance compared with current liquid electrolyte systems. The driving force for this advance is the strong potential for achieving high energy densities, high cell voltage, and superior self-discharge characteristics, while largely mitigating deficiencies, such as leakage, instability, and difficulty in the manufacture of large flat types, which are prevalent in currently used lithium-ion (Li-ion) batteries containing liquid electrolytes. ${ }^{1-3}$

The electrochemical properties of SPEs required for EV/HEV applications include: ionic conductivity greater than $10^{-3} \mathrm{~S} / \mathrm{cm}$ at room temperature, electrical conductivity less than $10^{-7} \mathrm{~S} / \mathrm{cm}$, electrical breakdown at greater than 5 volts $/ \mathrm{m}$, lithium ion transference number greater than 0.75 , and stability of the electrolyte adjacent to cathode material up to at least 4.5 volts versus lithium. Other desired features include high mechanical strength, thin film processibility, good interface properties, such as compatibility and adhesion, and smooth operation at ambient temperature. Moreover, the system must be amenable to mass production at reasonable cost.

At this time, a serious drawback of all solvent-free polymer electrolytes is their inadequate conductivities (much lower than $10^{-3} \mathrm{~S} / \mathrm{cm}$ ) at ambient temperatures. Among the solvent-free polymer electrolyte systems that 
PEO is still the best polymer matrix in terms of cost and overall electrolyte performance

Major challenge with PEO system is conductivity

Competitors of PEO have been investigated in the past two decades, polyethylene oxide (PEO) is the most studied system because of its several attractive features. The main advantages of $P E O$ as a host are its chemical, mechanical and electrochemical stabilities, since it contains only strong unstrained $C-O$, $\boldsymbol{C}-\boldsymbol{C}$, and $\boldsymbol{C}-\boldsymbol{H}$ bonds. PEO is very flexible (glass transition temperature, $\boldsymbol{T}_{\boldsymbol{g}}$ $=-61^{\circ} \mathrm{C}$ ) because of the presence of swivel ether linkages and the repeat unit, $-\mathrm{CH}_{2} \mathrm{CH}_{2} \mathrm{O}$-, provides just the right spacing for maximum dissolution of lithium salts. PEO electrolyte behaves like a rubbery material, due to the presence of sufficient interchain entanglement, and contains both crystalline and amorphous regions: the lithium ion conduction is believed to take place in the latter. ${ }^{\prime}$ PEO electrolytes also exhibit excellent melt processing capability which is very desirable for mass scale production of batteries.

Despite these attributes, the potential of the PEO system will remain impractical unless the room temperature conductivity is increased from $<10^{-5} \mathrm{~S} / \mathrm{cm}$ to the magic number $\left(>10^{-3} \mathrm{~S} / \mathrm{cm}\right)$. Although higher conductivities are preferable (similar to the aprotic liquid electrolytes currently used in Li-ion batteries $>10 \times 10^{-3} \mathrm{~S} / \mathrm{cm}$ ), 1000 -fold increases are not essential, as a thin-film electrochemical cell configuration can largely compensate for these lower values. ${ }^{1}$

In the past, extensive work has been performed with the PEO system and most researchers tend to believe that the saturation limit of room temperature conductivity is $\sim 10^{-4} \mathrm{~S} / \mathrm{cm}$ and that it is very unrealistic to achieve the magic number, $>10^{-3} \mathrm{~S} / \mathrm{cm}$. Other notable low $\mathrm{T}_{\mathrm{g}}$-based solventfree polymer electrolyte systems (viz. polyphosphazenes and polysiloxanes) are far behind PEO, primarily because of low dissolution of lithium salts in the polymer matrix. ${ }^{1-3}$ In recent years, many studies have been conducted to improve ionic conductivity of PEO electrolytes with regard to: (i) minimization of the crystallinity of PEO to make a fully amorphous polymer, ${ }^{4-6}$ (ii) investigation of the effect of mixing of nano-sized inorganic filler on the ionic conductivity of PEO composite, ${ }^{7-9}$ and (iii) addition of liquid plasticizer (both low and high molecular weight) to prepare PEO electrolyte. ${ }^{10-13}$ These approaches do not appear to achieve anywhere near the magic number.

Good ionic conductivity is essential to ensure that a battery system is capable of delivering usable amounts of power at a high rate, a critical requirement for EV/HEV batteries. It has been predicted that an SPE possessing room temperature conductivity near $10^{-3} \mathrm{~S} / \mathrm{cm}$ would lead to mass-scale production of long awaited and significantly safer, high energy density batteries. ${ }^{1-3}$ Accordingly, there is a compelling need for strategic design and development of an advanced polymer electrolyte system which is free of leakage and possesses high ionic conductivity and desired electrochemical and mechanical properties. 
Development of an SPE with high dielectric constant and low $T_{g}$ may provide solutions to lithium-polymer battery technology

\subsection{Technical Approach}

In Phase-I, TechDrive, Inc. proposed to revisit the PEO system because of its inherent attractive features (viz., salt dissolution, electrochemical stability, mechanical properties and low cost) that are not available in other polymer systems. In the Phase-I project, we focused on the two key parameters that are primarily responsible for the huge difference in conductivity between an SPE and liquid electrolyte. First, PEO has $a$ dielectric constant $(\varepsilon=6)$, much lower than those of polar aprotic solvents, such as ethylene carbonate $(\varepsilon=90)$, and results in stronger ion-ion interactions that markedly diminish both salt dissociation and ion mobility. Second, PEO possesses low $\mathrm{T}_{\mathrm{g}}$, which dramatically increases when lithium salts are introduced, thus creating a crystalline domain (lithium ions coordinated with PEO). Consequently, PEO electrolytes possess $T_{g} s$ much higher than the liquid electrolytes [e.g., $\mathrm{T}_{\mathrm{g}}$ of $1 \mathrm{M} \mathrm{LiPF}_{6}$ in $1: 1 \mathrm{EC} / \mathrm{DMC}$ is $<-100^{\circ} \mathrm{C}$ vs. the $\mathrm{T}_{\mathrm{g}}$ of $\mathrm{LiN}\left(\mathrm{SO}_{2} \mathrm{CF}_{3}\right)_{2} / \mathrm{PEO}$ composite containing $1: 12$ lithium:PEO is near $50^{\circ} \mathrm{C}$ ]. This difference results in a significant decrease in ion mobility in PEO at ambient temperatures. TechDrive's recent experimental observations on these two issues are extremely promising (vide infra). We are very optimistic that further studies at the molecular level will lead to an effective electrolyte system for use in the manufacture of a new generation of lithium batteries.

\subsection{Anticipated Public Benefits}

The achievement and availability of highly conductive polymer electrolytes would make a significant impact on consumer and EV/HEV technologies, as well as on military applications, such as electrically pulsed weapon systems for air defense, artillery and antiballistic missile weapons. Currently, federal agencies (DOE, Army, Navy, PNGV and USABC) and private industry (Duracell, Valence, 3M, Delphi and DuPont) are expending major financial resources in the area of Li-ion batteries. If the U.S. is to regain its leading role in the growing global market of Li-ion batteries, it is critical to perform research in cutting-edge areas. The program proposed here will strengthen U.S. industries' position as a major player in the emerging EV/HEV battery market and other high-power energy storage areas, such as cellular phone, computer, camcorder and power tool industries. 


\section{Degree to which Phase-I has Demonstrated Technical Feasibility}

In the Phase-I effort, we vigorously pursued two novel approaches to develop a promising PEO-based electrolyte system. The first approach is based on enhancing conductivity by increasing the dielectric constant of the SPE, while the second addresses the high $\mathrm{T}_{\mathrm{g}}$ problem by eradicating crystalline domains in the SPE, thereby markedly reducing $T_{g}$ of the SPE and leading to higher ionic conductivities. The rational design and our specific research accomplishments of these approaches are described below.

\subsection{Approach-1: High Carbonate Content SPE}

The addition of low molecular weight solvating diluents to PEO has been considered previously as a viable solution to circumvent the limitation of conductivity of PEO electrolytes. Diluents with high dielectric constants, such as propylene carbonate $(\varepsilon=65)$, which can simultaneously decrease $T_{g}$

Rational design of and promote salt dissociation, were among the first investigated. ${ }^{14-18}$ These TechDrive's dipolar diluents dramatically improve conductivity $\left(>10^{-3} \mathrm{~S} / \mathrm{cm}\right.$ at room polymeric temperature), but they are volatile, prone to leach out and are highly flammable. It occurred to us that a fruitful approach with strong potential would be to incorporate the favorable features of the carbonate moiety into the polymer matrix, without encountering the drawbacks of liquid carbonates. To our knowledge, there have been no studies with polymeric carbonate plasticizers as useful additives for PEO.

In our search for new high dielectric constant plasticizer systems, we identified poly(polytetrahydrofuran carbonate) diol (THFC) oligomer, which is inexpensive ( $1 \mathrm{~L}=\$ 64)$ and commercially available (Aldrich) in two molecular weights $\left(\mathrm{M}_{\mathrm{n}} \sim 1,000\right.$ and $\left.\sim 2,000\right)$. Since THFC is diol terminated, we performed two reactions in one pot to make it suitable for applications. The first reaction involves random copolymerization of THFC with polyethyleneglycol (PEG, also called PEO oligomer) in the presence of isophorone diisocyanate (IDI) as a connector. This reaction, shown in Figure 1, offers two attractive features: increase in molecular weight (solves the problem of drying by evaporation) and better compatibility with the PEO host (presence of PEO segments in the polymeric plasticizer). At the end of the first reaction (Step-1), we expect to have several reactive terminal hydroxyl groups of THFC and PEG. Since the presence of inert functional groups in the plasticizer is an essential requirement, we 
conducted a silylation reaction of the copolymer in the same pot, using hexamethylenedisilazane (HMDS, Step-2), thereby avoiding unwanted reactions of hydroxyl groups with electrode materials. Thus, a very convenient synthesis of an inert, relatively high dielectric constant carbonate-containing plasticizer (THFC-PEG) has been achieved. With inexpensive starting materials and both reactions proceeding in near quantitative yields, the THFC-PEG copolymer is obtained at relatively low cost. Moreover, the procedure can be readily scaled up because of one-pot reaction and no necessity of further purification.

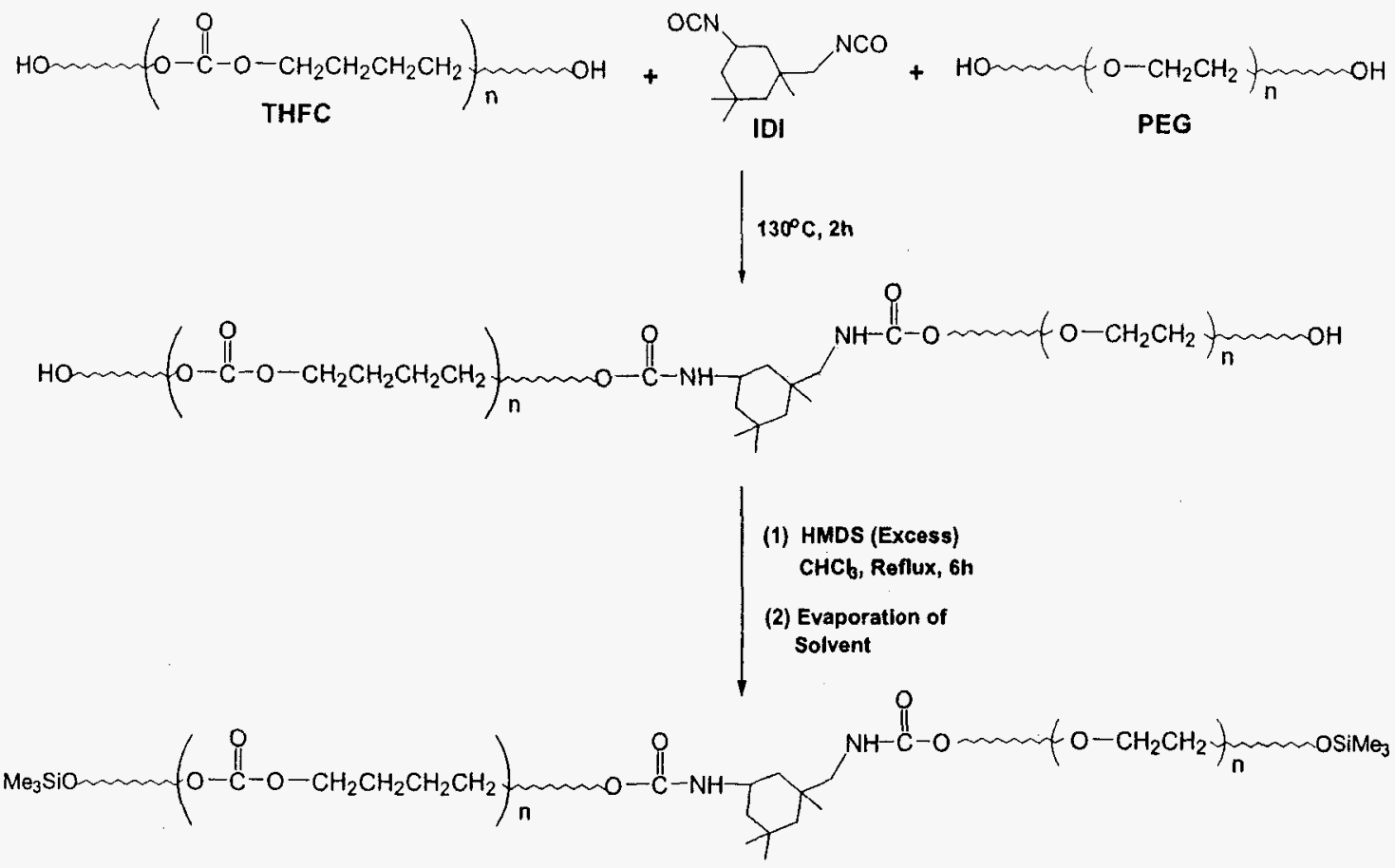

THFC-PEG

Figure 1. One-pot synthesis of THFC-PEG copolymer.

Since THFC-PEG possesses a high molecular weight (because of copolymerization), it is necessary to add a relatively low molecular weight non-volatile plasticizer to enhance the ionic conductivity of the electrolyte. We prepared a new PEO-based star-shaped plasticizer, BR $\boldsymbol{R}_{3}$ (Figure 2), which exhibited several favorable features: (i) low molecular weight multiple PEO segments within a higher molecular structure, (ii) possesses lower viscosity, owing to less inter-molecular attractions compared with methyl capped straight chain low molecular weight PEG, and (iii) displays 
no leach out or evaporation from the matrix, because of higher molecular weight molecule compared with traditional plasticizer, such as dioctylphthalate. $\mathrm{BR}_{3}$ was readily synthesized in one step by the reaction of M-PEG [methoxy poly(ethyleneglycol)], $\mathrm{CH}_{3} \mathrm{O}\left(\mathrm{CH}_{2} \mathrm{CH}_{2} \mathrm{O}\right)_{3} \mathrm{H}$, and boric acid anhydride $\left(\mathrm{B}_{2} \mathrm{O}_{3}\right)$ in refluxing toluene using a Dean-Stark apparatus to remove water of reaction. ${ }^{12}$



Figure 2. Synthesis of a'star-shaped plasticizer.

We evaluated the potential of these specifically designed plasticizers (THFC-PEG and $\left.\mathrm{BR}_{3}\right)$ using PEO as the host polymer $\left(\mathrm{M}_{\mathrm{w}} \sim 5,000,000\right)$ and 3M's lithium bis(trifluoromethylsulfonyl)imide (TFSI) as the lithium salt. The primary roles of these components are delineated below:

\begin{tabular}{|l|l|l|l|}
\hline \multicolumn{1}{|c|}{ PEO } & \multicolumn{1}{|c|}{ THFC-PEG } & \multicolumn{1}{c|}{ BR $_{\mathbf{3}}$} & \multicolumn{1}{c|}{ TFSI } \\
\hline $\begin{array}{l}\text { Mechanical } \\
\text { properties and } \\
\text { primary } \\
\text { conducting } \\
\text { medium }\end{array}$ & $\begin{array}{l}\text { Raise dielectric } \\
\text { constant of the } \\
\text { conducting } \\
\text { medium }\end{array}$ & $\begin{array}{l}\text { Lower the } \mathrm{T}_{\mathbf{g}} \text { of } \\
\text { the conducting } \\
\text { medium }\end{array}$ & $\begin{array}{l}\text { Highly efficient } \\
\text { lithium ion } \\
\text { source (high } \\
\text { thermal stability, } \\
\text { excellent for } \\
\text { melt processing) }\end{array}$ \\
\hline
\end{tabular}

As shown in Table 1, we prepared several formulations to study the effect of these additives in the PEO host. SPE- 1 is a control, while SPE-2, 3 and 4 offer the effect of individual plasticizers. For all initial measurements, we chose lithium salt concentrations at 1 equivalent of TFSI for 12 repeat units of ethylene oxide. This ratio has been proven to work best for the PEO system. ${ }^{1}$ Clearly, the carbonate plasticizer (THFC-PEG) is a much better additive in terms of conductivity (Table 1). We were very pleased to observe the room temperature $\left(27^{\circ} \mathrm{C}\right)$ conductivity of a PEO film containing 
$30 \mathrm{wt} . \%$ of THFC-PEG at $6.8 \times 10^{-5} \mathrm{~S} / \mathrm{cm}$ (SPE-2). The film quality and mechanical properties of this film were also very good, indicating excellent compatibility of THFC-PEG in PEO. BR 3 plasticizer, on the other hand, works best at $20 \mathrm{wt} . \%$ and showed relatively lower conductivity than THFC-PEG (SPE-3 and 4). However, the synergistic effect of these two plasticizers showed a remarkable improvement in conductivity $\left(2.2 \times 10^{-4}\right.$ $S / \mathrm{cm}$ ) without affecting compatibility and mechanical properties (SPE-5). Moreover, the $\mathrm{T}_{\mathrm{g}}$ of this formulation was also very low $\left(-16.3^{\circ} \mathrm{C}\right)$ compared to the PEO electrolyte (SPE-1) without these plasticizers $\left(49.5^{\circ} \mathrm{C}\right)$.

Table 1. Properties of High Carbonate Content SPE ${ }^{\mathrm{a}}$

\begin{tabular}{|c|c|c|c|c|c|c|}
\hline $\begin{array}{c}\text { Formulation } \\
\text { No. }\end{array}$ & $\begin{array}{c}\text { PEO } \\
\text { (g) }\end{array}$ & $\begin{array}{c}\text { THFC-PEG } \\
\text { (wt. ratio) } \\
\text { (g) } \\
\end{array}$ & $\begin{array}{c}\mathbf{B R}_{3} \\
(\mathrm{~g})\end{array}$ & $\begin{array}{c}\text { TFSI } \\
\text { (Li:O) }\end{array}$ & $\begin{array}{c}\text { RT Ionic } \\
\text { Conductivity } \\
(\mathbf{S} / \mathrm{cm}) \\
\end{array}$ & Objective \\
\hline SPE-1 & 100 & --- & -.- & $1: 12$ & $1.2 \times 10^{-6}$ & $\begin{array}{l}\text { Control for } \\
\text { comparison }\end{array}$ \\
\hline SPE-2 & 100 & $30(1: 4)$ & --- & $1: 12$ & $6.8 \times 10^{-5}$ & $\begin{array}{l}\text { Effect of } \\
\text { carbonate } \\
\text { plasticizer }\end{array}$ \\
\hline SPE-3 & 100 & -- & 20 & $1: 12$ & $8.3 \times 10^{-6}$ & \multirow{2}{*}{$\begin{array}{c}\text { Effect of } \mathrm{BR}_{3} \\
\text { plasticizer }\end{array}$} \\
\hline SPE-4 & 100 & $\cdots$ & 30 & $1: 12$ & $\ldots b$ & \\
\hline SPE-5 & 100 & $30(1: 4)$ & 20 & $1: 12$ & $2.2 \times 10^{-4}$ & \multirow{3}{*}{$\begin{array}{c}\text { Optimization } \\
\text { of carbonate } \\
\text { content in } \\
\text { THFC-PEG }\end{array}$} \\
\hline SPE-6 & 100 & $30(1: 2)$ & 20 & $1: 12$ & $--{ }^{b}$ & \\
\hline SPE-7 & 100 & $30(1: 1)$ & 20 & $1: 12$ & $\ldots b$ & \\
\hline SPE-8 & 100 & $40(1: 4)$ & 20 & $1: 12$ & $\ldots$ & $\begin{array}{c}\text { Performance } \\
\text { of THFC- } \\
\text { PEG }\end{array}$ \\
\hline SPE-9 & 100 & $30(1: 4)$ & 30 & $1: 12$ & $---{ }^{b}$ & $\begin{array}{l}\text { Optimization } \\
\text { of plasticizer } \\
\text { content }\end{array}$ \\
\hline SPE-10 & 100 & $30(1: 4)$ & 20 & $1: 10$ & $8.2 \times 10^{-5}$ & $\begin{array}{c}\text { Optimization } \\
\text { of salt } \\
\text { content }\end{array}$ \\
\hline
\end{tabular}

${ }^{\text {All }}$ conductivity measurements were performed at $27^{\circ} \mathrm{C}$.

${ }^{b}$ Measurement was not conclusive due to poor dimensional stability (high tackiness or not having good quality films) 
We then prepared several other films to study the effect of higher carbonate content THFC-PEG (SPE-6 and 7), higher loading of THFC-PEG (SPE-8), and higher loading of $\mathrm{BR}_{3}$ (SPE-9). Unfortunately, we were unable to prepare quality films suitable for conductivity measurement. Use of high carbonate content films led to phase segregated films. This incompatibility may be due to the presence of four methylene groups between two oxygen atoms as opposed to two methylene groups in PEO. We are attempting to address this problem by identifying a manufacturer (Empower Materials Inc., DE) who makes low molecular polyethylene carbonate (PEC), which may be a better starting material for future studies with this approach, in order to increase the proportion of carbonate groups in the SPE (vide infra). The films containing a higher proportion of $\mathrm{BR}_{3}$ exhibited high tackiness, unsuitable for further work. The use of higher concentrations of TFSI provided good films (SPE-10), but displayed lower conductivity.

We sought further strategies to enhance the conductivity of SPE-5 $\left(2.2 \times 10^{-4}\right.$ $\mathrm{S} / \mathrm{cm}$ ) to near the coveted $1 \times 10^{-3} \mathrm{~S} / \mathrm{cm}$. Recently, several papers have discussed the importance of aligning or organizing the polymer chains in order to enhance the levels of ionic conductivity. ${ }^{19,20}$ An improvement in conductivity of at least $1 / 2$ order in magnitude has been achieved by stretching or extrusion techniques, ${ }^{21,22}$ which provide orientation of PEO chains in the drawing direction. The oriented films are also known to exhibit better mechanical properties. Recently, we purchased a laboratory scale Three Roll Mill (Ross Equipment, NY) to make further progress on this idea in the Phase-I effort. Unfortunately, we could not complete the study due to inadequate horsepower of the motor to process high molecular weight PEO (rollers shut down due to overload) and lower attainable processing temperature (maximum $80^{\circ} \mathrm{C}$ by passing hot water through the rollers).

Further strategies to improve conductivity
In conclusion, with this emphasis (development of high carbonate content SPE), we prepared an SPE with a room temperature conductivity of $2.2 \times 10^{-4}$ $\mathrm{S} / \mathrm{cm}$. We are very optimistic that this approach has strong potential to enhance the conductivity to near the desired $1 \times 10^{-3} \mathrm{~S} / \mathrm{cm}$. This may be accomplished by using a new carbonate plasticizer containing a lesser number of methylene groups between two carbonate moieties (such as the aforementioned PEC) and by orienting the polymer chains in the drawing direction by use of high performance melt processing equipment. 


\subsection{Approach-2: Highly Amorphous, Low $T_{g}$ SPE}

In general, the $\mathrm{T}_{\mathrm{g}}$ of PEO increases dramatically with the addition of lithium salt, due to restriction of mobility of $P E O$ chains resulting from extensive coordination of lithium ions with ether linkages. If one hopes to achieve high room temperature conductivity of PEO-based electrolyte, the SPE must be amorphous and possess a $T_{g}$ much lower than room temperature since the transport of lithium ions is believed to occur through the amorphous (flexible) domains.

In Approach-I, we lowered the $T_{g}$ of the SPE by incorporating two specifically designed plasticizers, THFC-PEG and $\mathrm{BR}_{3}\left(\mathrm{~T}_{\mathrm{g}}\right.$ of SPE-5 is $\left.-16.3^{\circ} \mathrm{C}\right)$. In Approach-II, we adopted a novel strategy to prepare a highly amorphous SPE with a significantly lower $\mathrm{T}_{\mathrm{g}}$. The strategy involves breaking crystalline domains of PEO and/or introducing alternate lithium ion cordination sites

Rational design of TechDrive's low $T_{g} S P E$ using structurally PEO-like materials. While searching for suitable materials for this strategy, we selected a dendritic polyimine (DPI, $M W=\sim 7,000$, commercially available from Aldrich) because of its structural similarity with PEO. Compared with PEO, DPI exhibits much lower $\mathrm{T}_{\mathrm{g}}\left(-84^{\circ} \mathrm{C}\right)$ and similar power to dissolve high concentrations of lithium salts via chelation with $\mathrm{N}$ atoms. Unlike PEO, DPI possesses a large number of reactive groups $\left(64 \mathrm{NH}_{2}\right.$ per molecule), which must be nullified prior to SPE formulation (Figure 3).

We developed a very convenient method (one pot reaction!) to transform reactive DPI to a new class of unreactive $\mathrm{PEO}$-like material for obtaining a highly amorphous, low $\mathrm{T}_{\mathrm{g}}$ material. We chose to perform a Michael addition reaction involving an amine and acrylate (or acrylonitrile) (Figure 4). ${ }^{23}$ This type of reaction is normally very slow (especially with secondary amines, 10-14 days), but requires only two reactants, without any additive. This feature makes the reaction unique for SPE applications because no further purification is necessary. The reaction can be carried out either neat or in the presence of a small amount of solvent such as THF at a temperature near $50^{\circ} \mathrm{C}$. The completion of the reaction is easily monitored by following the disappearance of N-H peaks at $3330 \mathrm{~cm}^{-1}$ in the FT-IR spectrum. 


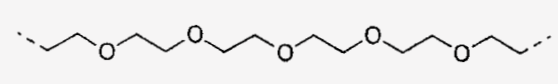

PEO

(Aldrich; MW=5,000,000)

$$
\mathrm{T}_{\mathrm{g}}=-61^{\circ} \mathrm{C}
$$

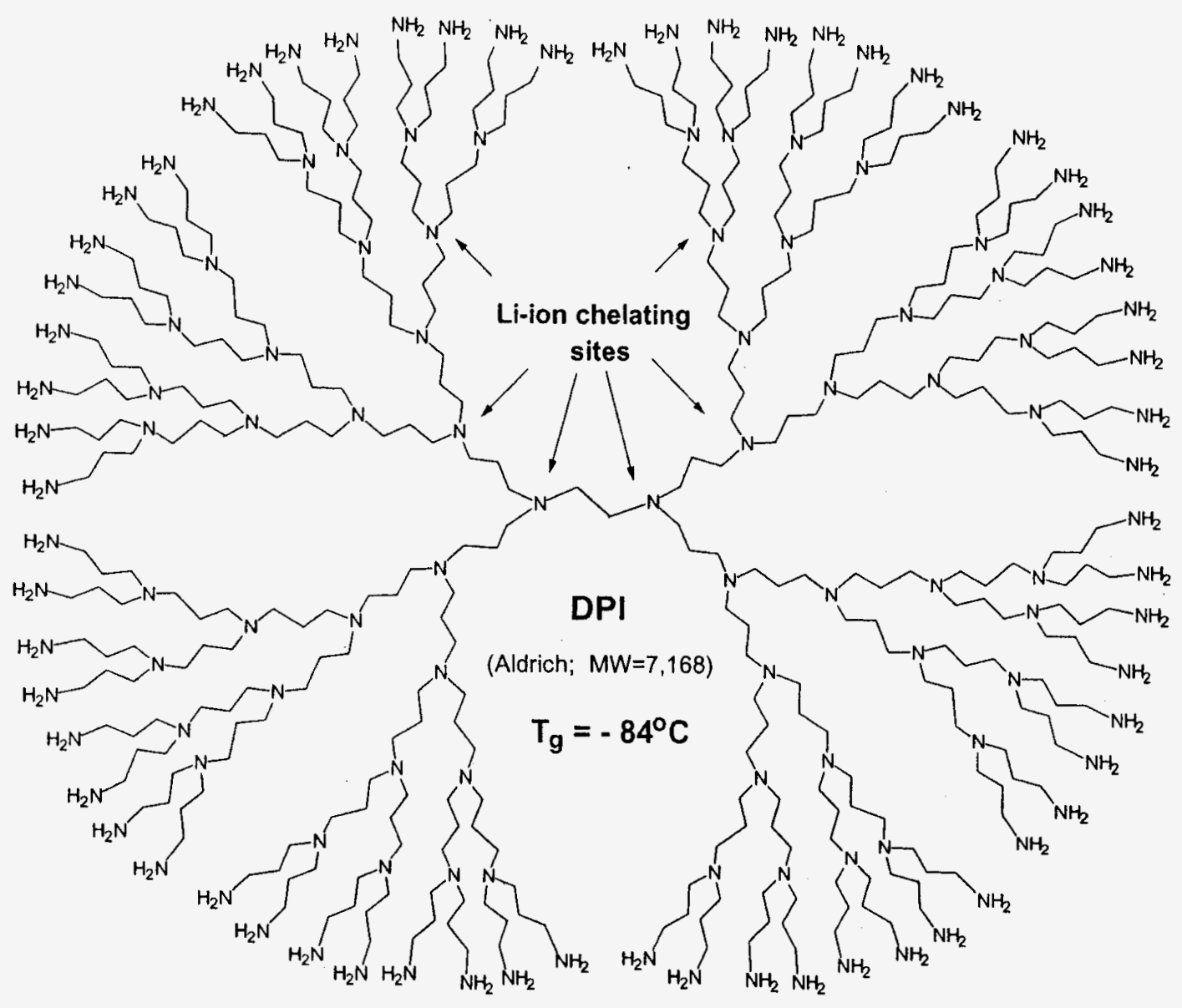

Figure 3. Structural comparisons of PEO and $5^{\text {th }}$ generation DPI. 
For simplicity, the reaction is shown with one amino group
REACTION WITH ACRYLATE
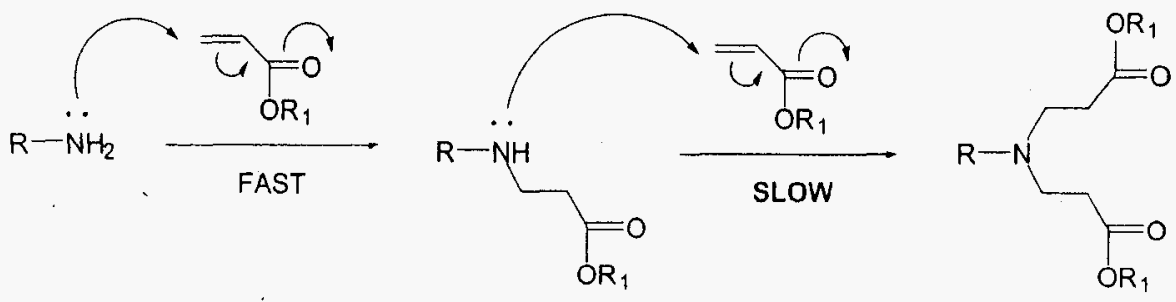

REACTION WITH ACRYLONITRILE
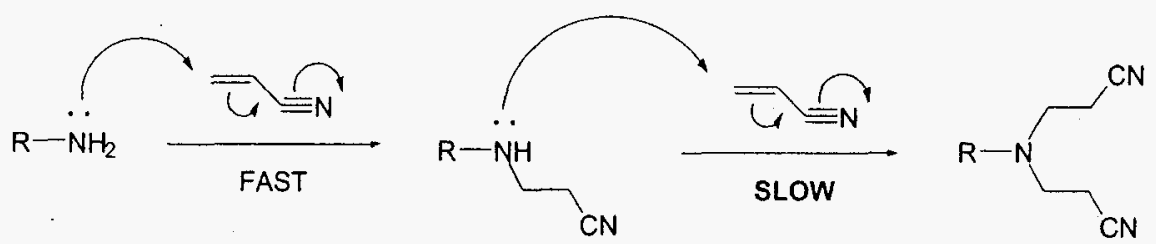

Figure 4. Michael addition reaction.

We carefully selected poly(ethylene glycol) methyl ether acrylate (PEGAC) and acrylonitrile (AN) from a variety of protective additives. Both materials possess attractive features along with weak points. As shown in Figure 5, PEG-AC reacts with DPI and forms a larger radius dendritic copolymer, DPI-PEG. The great advantage of this copolymer is the presence of both a crystallization prevention region (DPI) and high PEO compatibility region (PEG) in the same polymer. The disadvantage of using PEG-AC is uncertainty in protecting all relatively less reactive $\mathrm{NH}$ groups (after addition of one molecule of reactant to an amino group). Since PEG$\mathrm{AC}$ possesses a high molecular weight and is difficult to distill below $100^{\circ} \mathrm{C}$, whatever proportions are chosen, there will always be a residue of a few reactive secondary amino groups or excess of PEG-AC. Either situation is impractical for good electrochemical stability of the SPE films.



Figure 5. Synthesis of DPI-PEG copolymer (reaction of PEG-AC with DPI). 
By contrast, AN, a small molecule with a low boiling point $\left(77^{\circ} \mathrm{C}\right)$, will introduce a large number of highly polar nitrile $(\mathrm{CN})$ groups at the peripheral sites of DPI (DPI-AN in Figure 6). We reasoned that AN may have, perhaps, two major advantages. First, it may enhance the polarity (dielectric constant) of the PEO electrolyte because of the introduction of a large number of polar nitrile groups. Second, since $A N$ is a low boiling solvent, it can be used in excess to react with all $\mathrm{NH}$ and $\mathrm{NH}_{2}$ groups, and subsequently be removed completely from the reaction mixture by vacuum distillation. We noticed afterwards a major disadvantage of AN is that the SPEs derived from PEO and DPI-AN exhibit very high shrinkage (significantly contract into thicker, wrinkled films immediately after hot pressing the SPE), due perhaps, to strong intermolecular forces among the large number of $\mathrm{CN}$ groups, which act like a crosslinker.

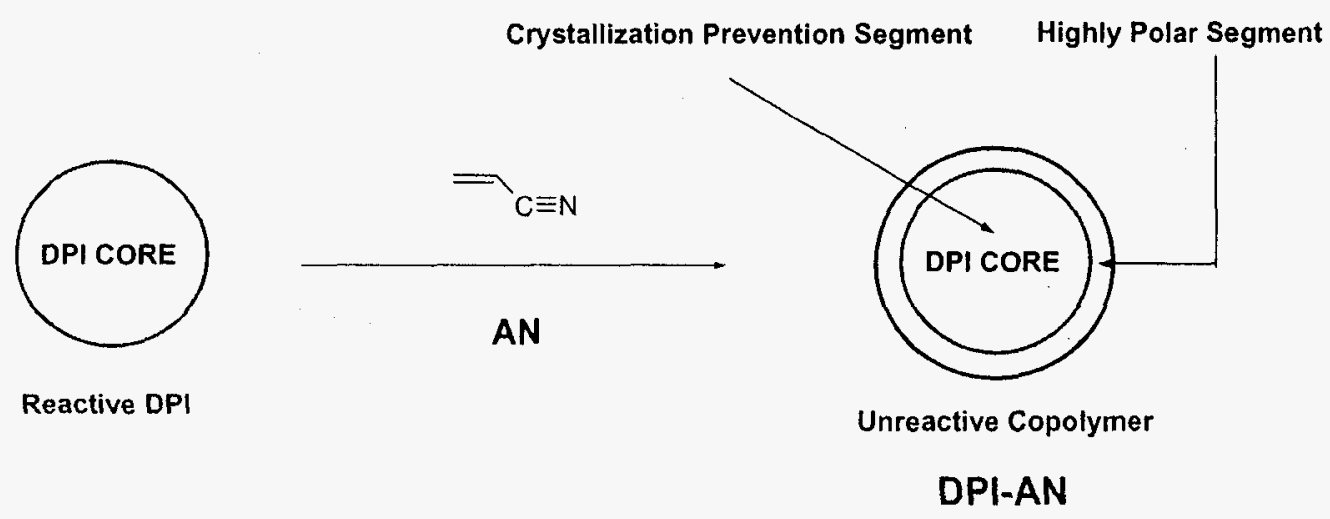

Figure 6. Synthesis of DPI-AN copolymer (reaction of AN with DPI).

\section{Ionic Conductivity:}

We then prepared and characterized several SPE films according to the formulations depicted in Table 2. We observed a remarkable improvement in conductivity $\left(7.48 \times 10^{-4} \mathrm{~S} / \mathrm{cm}\right.$, SPE-12) with the use of PEG-modified dendritic polyimine (DPI-PEG). We believe that this enhancement in conductivity is attributable to the destruction of crystalline PEO-lithium salt micro-domains.

We confirmed this belief by $X$-ray analysis. As seen in Figure 7, the standard electrolyte (SPE-1) shows small crystalline peaks, while the DPIPEG fortified electrolyte (SPE-12) does not show such peaks. 
Table 2. Properties of Low $T_{g} S P E^{a}$

\begin{tabular}{|c|c|c|c|c|c|c|c|}
\hline $\begin{array}{c}\text { Formulation } \\
\text { No. }\end{array}$ & $\begin{array}{l}\text { PEO } \\
\text { (g) }\end{array}$ & $\begin{array}{c}\text { DPI- } \\
\text { PEG }^{\text {c }} \\
(\mathrm{g}) \\
\end{array}$ & $\begin{array}{c}\text { DPI-AN } \\
(\mathrm{g})\end{array}$ & $\begin{array}{c}\text { TFSI } \\
(\mathbf{L i}: \mathbf{O} / \mathrm{N})\end{array}$ & $\begin{array}{c}\text { RT Ionic } \\
\text { Conductivity } \\
(\mathrm{S} / \mathrm{cm}) \\
\end{array}$ & $\begin{array}{l}\mathrm{T}_{\mathrm{g}} \\
\left({ }^{\circ} \mathrm{C}\right)\end{array}$ & Objective \\
\hline SPE-1 & 100 & --- & --- & $1: 12$ & $1.2 \times 10^{-6}$ & 49.5 & $\begin{array}{l}\text { Control for } \\
\text { comparison }\end{array}$ \\
\hline SPE-12 & 100 & 50 & -- & $1: 12$ & $7.48 \times 10^{-4}$ & -33.5 & \multirow{3}{*}{$\begin{array}{c}\text { Effect of DPI- } \\
\text { PEG }\end{array}$} \\
\hline SPE-13 & 100 & 60 & -- & $1: 12$ & $8.62 \times 10^{-4}$ & -35.2 & \\
\hline SPE-14 & 100 & 70 & $\ldots$ & $1: 12$ & $-{ }^{b}$ & $\ldots$ & \\
\hline SPE-15 & 100 & -- & 50 & $1: 12$ & $\ldots b$ & -- & $\begin{array}{c}\text { Effect of DPI- } \\
\text { AN }\end{array}$ \\
\hline
\end{tabular}

All conductivity measurements were performed at $27^{\circ} \mathrm{C}$.

${ }^{b}$ Measurement was not conclusive due to low dimensional stability (high tackiness or not having good quality films).

c. Synthesis of DPI-PEG: This copolymer was prepared by reacting DPI with 125 times mole excess of PEG-AC at $50^{\circ} \mathrm{C}$ in THF. After 10 days, 25 times mole excess of AN was added and reaction continued for another 10 days at $50^{\circ} \mathrm{C}$. The latter operation ensures absence of PEG-AC and complete disappearance of any reactive amino groups. Excess solvent and AN were removed under reduced pressure.

d. Synthesis of DPI-AN: This unreactive DPI derivative was prepared by reacting DPI with 200 times mole excess of $\mathrm{AN}$ at $50^{\circ} \mathrm{C}$ in THF. After 10 days, $\mathrm{AN}$ was removed under reduced pressure.

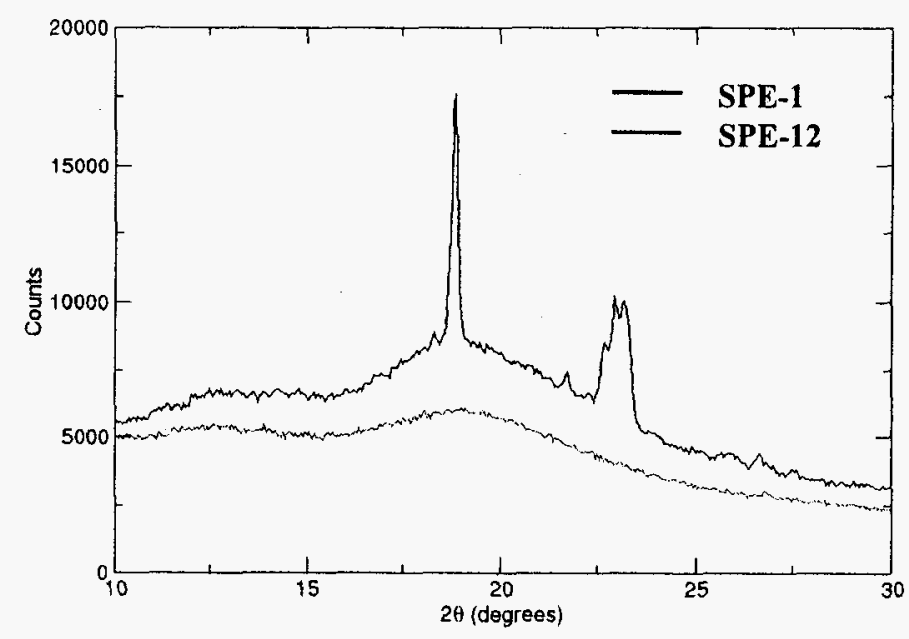

Figure 7. X-ray diffraction analysis of standard and low $\mathrm{T}_{\mathrm{g}}$ electrolytes. 
Although the best conductivity was obtained with SPE-13, we chose to pursue further studies with SPE-12 because of superior film quality.

Physically, it appears as a very dry, translucent, and rubbery material with high elastic recovery (Figure 8). The overall performance of SPE-12 is described in Table 3.

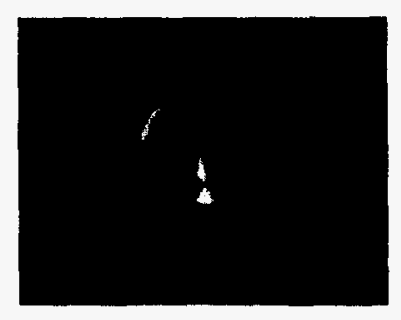

Dry and translucent

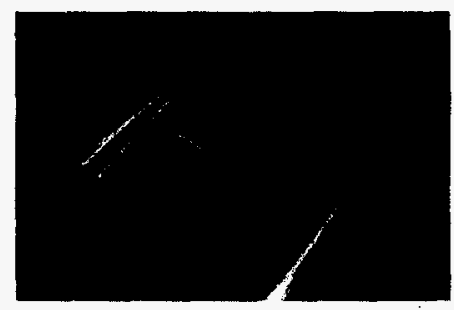

Release of stretching recovery (quick relaxation to its original state)

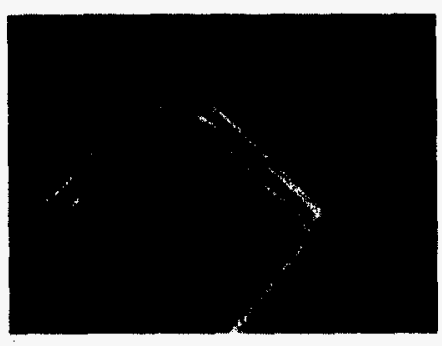

Effect of stretching
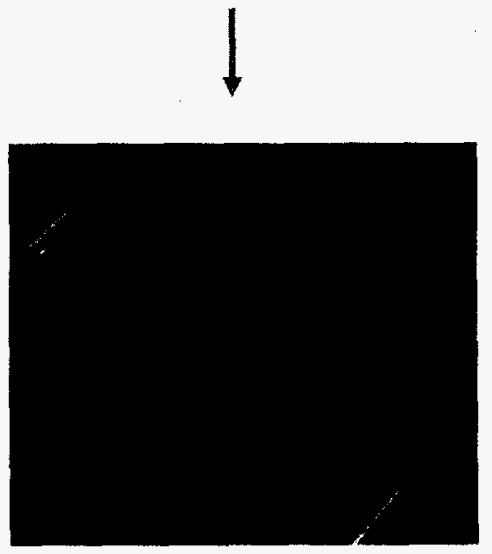

Further Stretching (Tough and high strength)

Figure 8. Elastic behavior of SPE-12.

Table 3. Properties of SPE-12

\begin{tabular}{|c|c|c|c|c|c|}
\hline $\begin{array}{c}\mathbf{T}_{\mathbf{g}} \\
\left({ }^{\circ} \mathrm{C}\right)\end{array}$ & $\begin{array}{c}\text { PDT }^{\mathbf{a}} \\
\left({ }^{\circ} \mathbf{C}\right)\end{array}$ & $\begin{array}{c}\text { RT Ionic } \\
\text { Conductivity } \\
(\mathbf{S} / \mathbf{c m})\end{array}$ & $\begin{array}{c}\text { Electrochemical } \\
\text { Stability } \\
(\mathbf{V})\end{array}$ & $\begin{array}{c}\text { Cycling } \\
\text { Characteristics }\end{array}$ & $\begin{array}{c}\text { Mechanical } \\
\text { Properties }\end{array}$ \\
\hline-33.5 & 403 & $\mathbf{7 . 4 8 \times 1 0 ^ { - 4 }}$ & $>4.5$ & Very good & Excellent \\
\hline
\end{tabular}

${ }^{\mathrm{a}} \mathrm{PDT}=$ Product decomposition temperature. 


\section{Electrochemical Stability:}

SPE-12 also displayed good electrochemical stability (Figure 9). Minor irregularities around $4.5 \mathrm{~V}$ were observed, perhaps derived from the small percentage of stabilizers present in acrylonitrile. These impurities can be removed by using freshly distilled acrylonitrile, which we plan to revisit in our future work.

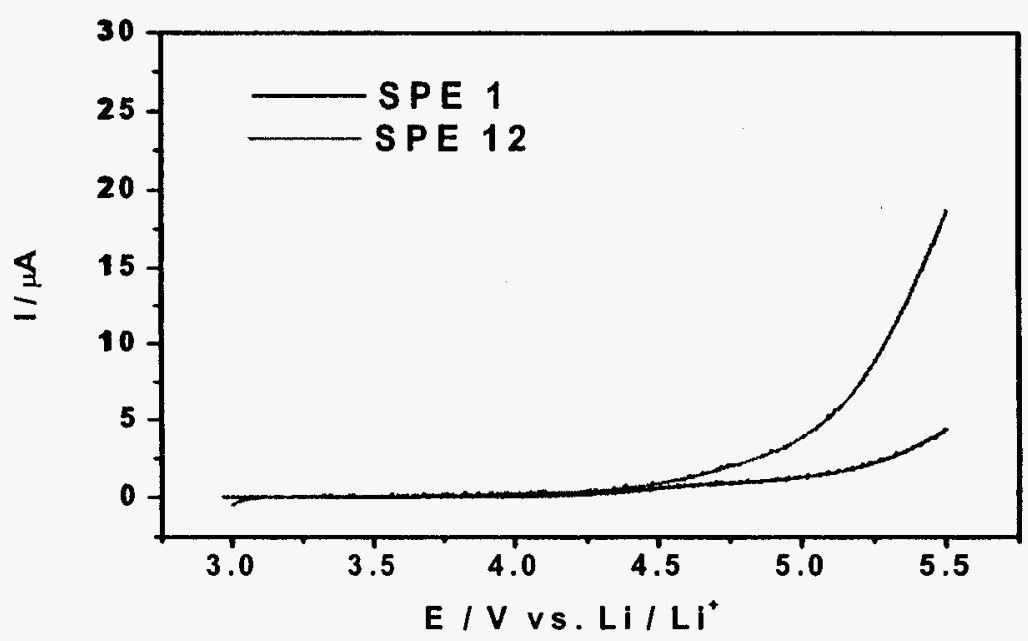

Figure 9. Cyclic voltammetry of SPE-12.

\section{Mechanical Properties:}

With these very encouraging results, it was quite appropriate to perform studies of dynamic rheological properties using a dynamic mechanical spectrometer (Rheometrics-RMS-800). As mentioned earlier, for practical applications, an SPE must be melt processible into thin films. Dynamic rheological studies provide a complete picture of several mechanical and processing parameters. In Phase-I, we have conducted a comprehensive study, in order to assess the mechanical and processing performances of SPE-12. The results obtained at $75^{\circ} \mathrm{C}$ indicate that this is the best processing temperature. We present here only three important studies to describe the versatility of this experiment. Figure 10a, which is a plot between stress-relaxation vs. time, shows that SPE-12 possesses far superior mechanical properties than that of the control [modulus: SPE-12 $=5.5 \times 10^{5}$ dynes $/ \mathrm{cm}^{2}$; SPE-1 (blue line) $=9.1 \times 10^{4}$ dynes $/ \mathrm{cm}^{2}$ ]. SPEs with higher modulus exhibit better dimensional stability. This figure also shows that the stress-relaxation of SPE-12 is much faster than the control, and indicates a very favorable property for extruded films.

Figure 10b shows that SPE-12 possesses very high viscosity, $1 \times 10^{7}$ poise, which is a very favorable number for processing. Figure $10 \mathrm{c}$ is a dual plot 
of viscous or loss modulus and storage or elastic modulus vs. frequency. This study helps to determine crossover frequency (the point two curves meet), a parameter which provides the means to calculate relaxation time. The relaxation time for SPE- 12 is $\sim 323$ seconds. These relaxation times can be used to control the quality of manufacturing from batch to batch, so long as repeated measurements are within \pm 5 seconds.
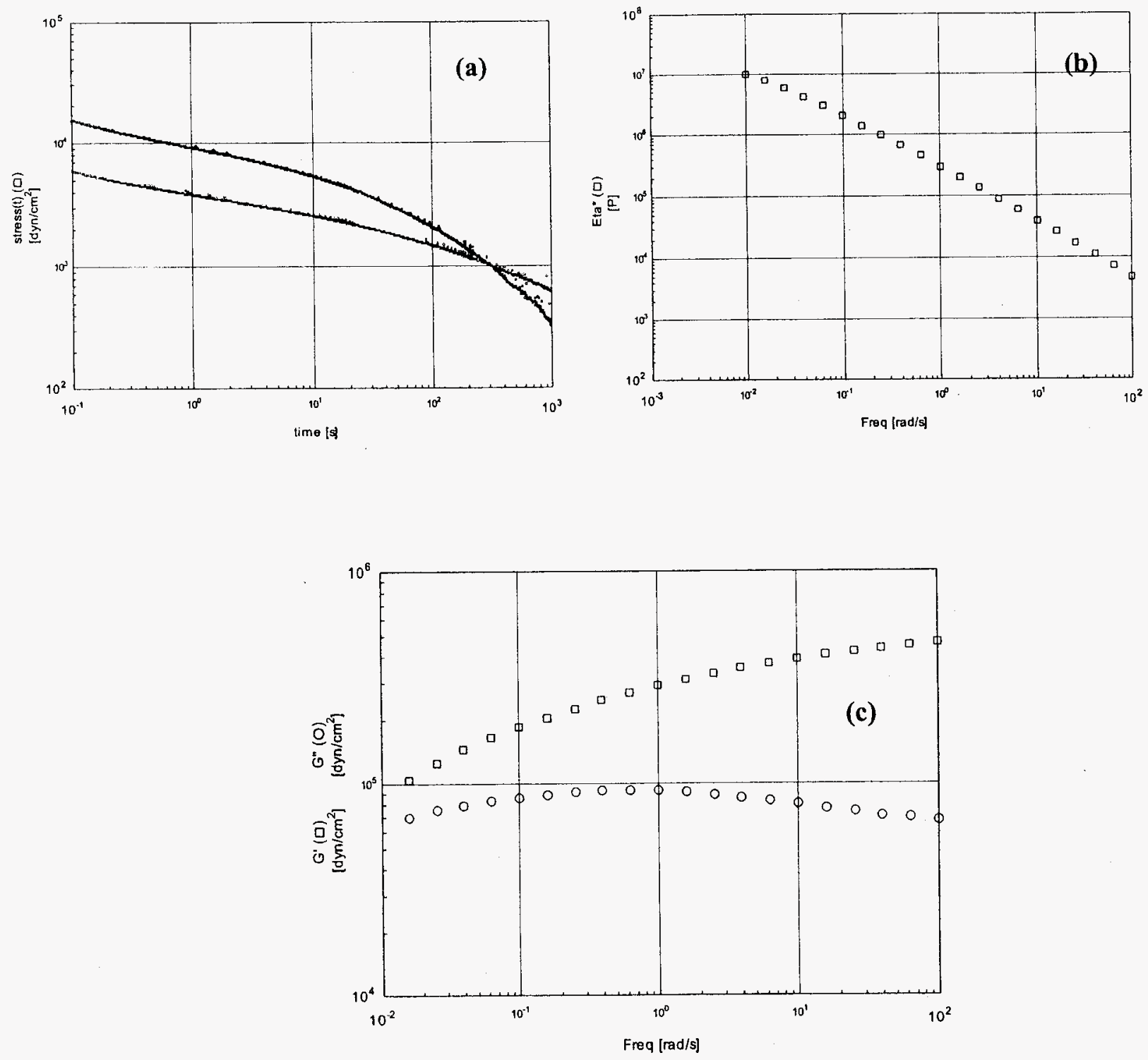

Figure 10. Rheological properties of SPE-12: (a) stress-relaxation vs. time (blue line is for SPE-1); (b) complex viscosity vs. frequency; (c) frequency dependent studies: (circle) viscous or loss modulus; (square) storage or elastic modulus. 


\section{Thermal Properties:}

From our experience with SPEs, we conclude that an SPE derived from PEO and DPI-PEG (e.g., SPE-12) would require high pressure ( $\sim 5000 \mathrm{psi})$ and $75^{\circ} \pm 10^{\circ} \mathrm{C}$ for thin film processing. Therefore, it is very important that an SPE survive these projected conditions. Thermogravimetric analysis (TGA) of SPE- 12 shows excellent thermal properties, as demonstrated by no weight loss before $400^{\circ} \mathrm{C}$ (Figure 11). Minor loss around $125^{\circ} \mathrm{C}$ points to the removal of a small amount of absorbed moisture while preparing/loading the sample outside of the glove box for TGA analysis. Differential scanning calorimetry (DSC) also showed that SPE-12 possesses a very low $\mathrm{T}_{\mathrm{g}}$ $\left(-33.5^{\circ} \mathrm{C}\right)$, an essential requirement for having high conductivity, the major theme of our research and development (Table 2).

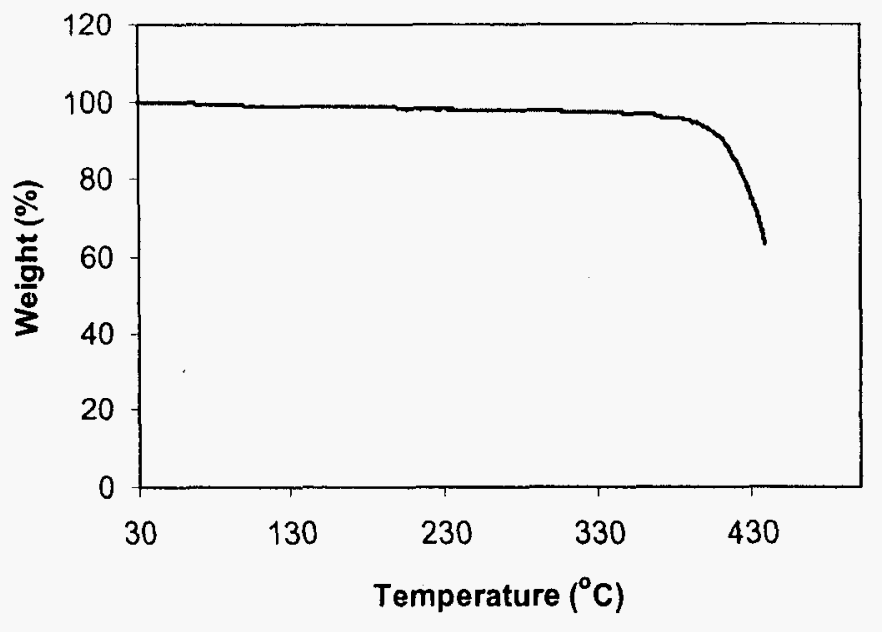

Figure 11. TGA trace of SPE- $12\left(10^{\circ} \mathrm{C} / \mathrm{min}\right.$, argon $)$.

\section{Cycling Characteristics:}

Figure 12 shows the charge/discharge curves of an $\mathrm{Li} / \mathrm{SPE} 12 / \mathrm{LiNi}_{0.8} \mathrm{Co}_{0.2} \mathrm{O}_{2}$ cell at $40^{\circ} \mathrm{C}$. When this cell was cycled at low current rate $(\mathrm{C} / 15)$, a relative high discharge capacity $(\sim 110 \mathrm{mAh} / \mathrm{g})$ was obtained at the first cycle. The capacity of this cell still remained as high as $101 \mathrm{mAh} / \mathrm{g}$ after 15 cycles, while the charge/discharge efficiency of the cell is over $97 \%$, indicating a good cycle property. The effect of discharge rates on the discharge capacity is currently being investigated in our lab. However, these preliminary data are very promising. Detailed studies involving full cells and various rates will be part of the Phase-II project. 




Figure 12. Charge/discharge curves of $\mathrm{Li} / \mathrm{SPE} 12 / \mathrm{LiNi}_{0.8} \mathrm{Co}_{0.2} \mathrm{O}_{2}$ cell for the first 15 cycles at $40^{\circ} \mathrm{C}$. The cell was cycled between 3.0 to $4.2 \mathrm{~V}$ vs. $\mathrm{Li}^{2} \mathrm{Li}^{+}$and the charge/discharge current rate is about $\mathrm{C} / 15$.

In conclusion, we are persuaded that our results have debunked the long held myth "PEO-based SPE electrolyte is not practical" and we are very enthusiastic about the overall properties of SPE-12 (especially, conductivity, mechanical, and thermal properties). Another notable aspect of this formulation is that it is free of plasticizers (such as $\mathrm{BR}_{3}$, which is essential in the previous approach). We are confident that the desired conductivity of $1.0 \times 10^{-3} \mathrm{~S} / \mathrm{cm}$ will be exceeded by aligning the polymer chains in the film-draw direction. This study could not be completed due to the unavailability of the requisite equipment. 


\section{References}

1. Handbook of Battery Materials, J. O. Besenhard, Ed., Weinheim, New York, 1999.

2. Polymer Electrolytes, F. M. Gray, RSC Monographs, The Royal Society of Chemistry, London, 1997.

3. Handbook of Batteries, D. Linden, Ed., McGraw-Hill, $2^{\text {nd }}$ Edn., New York, 1995.

4. R. Frech, J. Manning, D. Teeters and B. E. Black, Solid State Ionics, 28-30, 954 (1988).

5. T. Itoh, N. Hirata, Y. Moriya, M. Kubo and O. Yamamoto, J. Power Sources, 81-82, 825 (1999).

6. Z. Wang, M. Ikeda, N. Hirata, M. Kubo and T. Itoh, J. Electrochem. Soc., 146(6), 2209 (1999).

7. F. Croce, G.B. Appetecchi, L. Persi and B. Scrosati, Nature, 394, 456 (1988).

8. A. S. Best, A. Ferry, D. R. MacFarlane and M. Forsyth, Solid State Ionics, 126, 269 (1999).

9. H. Y. Sun, H. J. Sohn, O. Yamamoto, Y. Takeda and N. Imanishi, $J$. Electrochem. Soc., 146(5), 1672 (1999).

10. F. Croce, S.D. Brown, S.G. Greenbaum, S.M. Slane and M. Solomon, Chem. Mater., 5, 1268 (1993).

11. J. Y. Kim and S. H. Kim, Solid State Ionics, 124, 91 (1999).

12. Y. Kato, K. Hasumi, S. Yokoyama, T. Yabe, H. Ikuta, Y. Uchimoto, M. Wakihara, Solid State Ionics, 150, 355 (2002).

13. Y. Kato, K. Hasumi, S. Yokoyama, T. Yabe, H. Ikuta, Y. Uchimoto, M. Wakihara, $J$. Thermal Analysis and Calorimetry, 69, 889 (2002).

14. I. Kelly, J.R. Owen, B.C.H. Steele, J. Power Sources, 14, 13 (1985).

15. M. Z. Munsi, B.B. Owens, Solid State Ionics, 26, 41 (1988).

16. G. G. Cameron, M. D. Ingram, K. Sarmouk, Eur. Polym. J., 26, 1097 (1990).

17. D. G. H. Ballard, P. Cheshire, T. S. Mann, J. E. Przeworski, Macromolecules, 23, $1256(1990)$.

18. R. Huq, G. C. Farrington, R. Koksbang, P.E. Tonder, Solid State Ionics, 57, 277 (1992).

19. Y. G. Andrew and P. G. Bruce, Electrochim. Acta., 45, 1417 (2000).

20. Z. Gadjourova, D. M. Marero, K.H. Anderson, Y.G. Andreev, and P.G. Bruce, Chem. Mater., 13, 1282 (2001).

21. P. V. Wright, Y. Zheng, D. Bhatt, T. Richardson, G. Ungar, Polym. Int. 47, 34 (1998).

22. D. Golodnitsky and E. Peled, Electrochim. Acta., 45, 1431 (2000).

23. E. Berg and E. W. Meijer, Angew. Chem. Int. Ed. Engl. 32(9), 1308 (1993) and references therein. 